\title{
An analysis of environmental corporate social responsibility
}

\begin{abstract}
This article investigates corporate social responsibility (CSR) practices while taking into account their product substitutability and environmental responsibility. CSR firms, integrating environmental and social concerns into its business operations, are introduced. The effects of the firms' social concerns, environmental responsibility and product substitutability are all captured. First, firms' social concerns improve both outputs and CSR firms' objective function value, while reducing the profit maximization firm's profits. Second, environmental responsibility has the contrary effects. Both the outputs and the objective function values of both firms decrease with their product substitutability. Finally, social concern effects on CSR firms' performance are uncertain.
\end{abstract}

Keywords: corporate social responsibility (CSR), environmental responsibility, emission, social concerns, environmental CSR

\section{Introduction}

There are many definitions of CSR. The World Business Council for Sustainable Development defined CSR as "the continuing commitment by business to behave ethically and contribute to economic development while improving the quality of life of the workforce and their families as well as of the local community and society at large". (http://www.mallenbaker.net/csr/definition.php). According to the recent interesting paper of Benabou and Tirole (2010), corporate social responsibility (CSR) is defined as "about sacrificing profits in the social interest". Corporate social responsibility (CSR) plays very important role in the whole society. According to the data about CSR in 2008, about $80 \%$ of the largest 250 firms in the world issued CSR reports (KPMG, 2008). Fernandez-Kranz and Santalo (2010) and Starks (2009)

This is the author manuscript accepted for publication and has undergone full peer review but has not been through the copyediting, typesetting, pagination and proofreading process, which may lead to differences between this version and the Version of Record. Please cite this article as doi: 10.1002/mde.3009

This article is protected by copyright. All rights reserved. 
pointed out that both investors and consumers put increasing pressure on firms to consider social and environmental responsibility alongside business goals. CSR may act as an important strategy of firms (Wang, Tong, Takeuchi \& George, 2016; Marin et al., 2012; Schrempf, 2012; Chen, Wen and Luo, 2016; Chen and Nie, 2016;Wang and Nie, 2016; Wang and Nie, 2018a; Nie, Wang, Chen and Chen, 2018; Kim,2017; Yang, Nie, Liu \& Shen, 2018; Nie, 2018; Nishitani, Jannah \& Kaneko, 2017; Nie, Wang \& Chen, 2018; Wang \& Nie,2018b; Nie \& Wang, 2019; Chen, Wen, Wang \& Nie, 2017).

CSR attracts intensive attentions of economists in recent years and there are three interesting review papers about CSR. McWilliams, Siegel and Wright (2006) significantly reviewed the early main research about CSR. Carroll and Shabana (2010) further reviewed the literature abut the concept, the research and the application about CSR community. Kitzmueller and Shimshack (2012) recently reviewed the statues of the significant research on CSR.

CSR has important effects on firms' strategies, including managerial contracting (Baron, 2008; Flammer, 2018; Flammer, 2015b), financial performance (Besley and Ghatak, 2007; Orlitzky et al.,2003; Flammer, 2013; Cheng, Ioannou, \& Serafeim, 2014), and the consumers' behaviors (Mohret al., 2001; Nie, Wang, Chen \& Yang, 2018; Flammer \& Luo, 2017; Fikse \& Lal, 2018). Much literature in economics focuses on the relationship between the social performance and the corporate financial performance. In empirical studies, with data from S\&P 500 firms, Hillman and Keim (2001) examined early the positive links between CSR and the firms' performance. With a two-stage model, Brammer and Millington (2008) also explored how good social performers do better over longer time horizons. Chen, Nie and Yang (2017) recently argued that CSR can improve food quality.

In theory, Kopel (2011) pointed out that theoretical research neglects CSR until recently and the theoretic analysis about the relationship between the CSR and firm's performance seems rare. By a two-stage model, Goering (2010) showed that a firm may earn higher profits as it increases its level of corporate social responsibility (CSR). The basic theoretic conclusions are consistent with the empirical results. Recently, Kopel and Brand (2012) established a theoretical model and argued 
that socially concerned firms have higher profits if the marginal costs are similar. When the share of CSR increases, the socially concerned firm's profit first increases then decreases (Wang, Nie \& Meng, 2018).

In empirical and experiment field, Caroline Flammer with his group did very excellent job (Flammer, 2013, 2015, 2015b, 2018). With corporate news related to environment for all US publicly traded companies from 1980 to 2009, Flammer (2013) identified that higher levels of environmental CSR relate to smaller stock market reaction to eco-friendly (-harmful) events. Based on a quasi-experiment to study the effect of CSR on performance, Flammer (2015b) concluded that firms benefit from adopting close call CSR proposals. With import tariff reductions between 1992 and 2005 in the US manufacturing sector, Flammer (2015) argued that CSR as a competitive strategy.

Although massive papers appear in recent years, scare literature exists about environmental CSR. Actually, environmental issue attracts more and more attention in recent years. Wang, Tong, Takeuchi \& George (2016) also pointed out that "businesses in developed countries may face stronger expectations on environmental responsibility and stewardship of natural resources." Therefore, it is very important to address environmental CSR. Moreover, to advocate environmental CSR, it is important to capture the effects of environmental CSR.

This paper further develops the theoretic analysis of the relationship between environmental CSR and firms' performance. Following the interesting papers of Goering $(2008,2010)$ and, Kopel and Brand (2012), the effects of the CSR on firms' performance are addressed. Compared with the early theoretical literature, this article introduces environment responsibility and product substitutability. Flammer (2013) focused on the stock market reaction of environmental CSR, while this article focuses on the theoretical analysis.

Compared with the existing conclusions, this paper finds that social concerns improve both the outputs and the objective function value of the CSR firm, while reducing the profit maximization (PM) firm's profits. Environmental responsibility reduces both the outputs and the objective function value of the CSR firms, while improving the PM firm's profits. Moreover, the 
effects of product substitutability are also addressed. Interestingly, because of environmental responsibility and product substitutability, the relationship between CSR and CSR firm's performance is uncertain.

The rest of this paper is organized as follows: The model is established in Section 2. For the model in this section, both social concerns and environmental responsibility are addressed. Moreover, product substitutability is also introduced in this model. Section 3 analyzes the model and the effects of the social concerns, environmental responsibility and product substitutability are all addressed. The effects of the CSR on CSR firm's performance are investigated in Section 4. Some concluding remarks are presented in the final section.

\section{Model}

The model of firms with CSR is established. There are two firms in this industry. One is a firm with CSR practices and the other is a profit maximizing (PM) one. Denote the two firms to be $k \in\{C S R, P M\}$. The CSR firm integrates environmental responsibility and social concerns into its business operations. The PM firm maximizes its profits. Denote the price to be $p=\left(p_{C S R}, p_{P M}\right)$ and the quantity of the outputs to be $q=\left(q_{C S R}, q_{P M}\right)$.

\subsection{Consumers}

The utility of the consumer is assumed as follows (Eq. 1):

$$
U\left(q_{C S R}, q_{P M} ; p_{C S R}, p_{P M}\right)=\alpha\left(q_{C S R}+q_{P M}\right)-\frac{1}{2} q_{C S R}^{2}-\frac{1}{2} q_{P M}^{2}-q_{P M} p_{P M}-q_{C S R} p_{C S R}-\gamma q_{P M} q_{C S R} \cdot
$$

In (1), $\alpha>0$ is a constant and $\gamma \in[0,1] . \quad \alpha>0$ indicates the total market size, and $\gamma \in[0,1]$ manifests the degree of product substitutability. $\gamma=0$ means that the two goods are independent, while $\gamma=1$ stands for perfect substitutes (Nie and Chen, 2012; Nie, 2014).

The linear inverse demand function is employed. For $i, j \in\{C S R, P M\}$ and $i \neq j$, 


$$
p_{i}=\alpha-q_{i}-\gamma q_{j}
$$

Eq. 2 is directly induced by Eq. 1.

\subsection{Producers}

Here the firms are modelled. Denote the marginal costs incurred by production to be $\left(c_{C S R}, c_{P M}\right)$. To simplify, this paper always assumes that $c_{C S R}=c_{P M}=c . E_{i}=\beta q_{i}$ denotes the environment externality (or emission) of the firm along with the outputs $q_{i}$, where $\beta>0$ is a parameter. Moreover, $E=E_{C S R}+E_{P M}=\beta\left(q_{C S R}+q_{P M}\right)$ stands for the total environment externality of the total emission in this industry. This environmental externality is introduced by Lambertini and Tampieri (2010). For the CSR firm, the objective is to maximize Eq.3.

$$
V_{C S R}=\left(\alpha-q_{C S R}-\gamma q_{P M}-c\right) q_{C S R}+\frac{\mu}{2}\left(q_{C S R}^{2}+q_{P M}^{2}+2 \gamma q_{P M} q_{C S R}\right)-\beta q_{C S R} .
$$

In Eq.3, $1 \geq \mu \geq 0$ stands for the degree of the social concerns. In Eq.3, the term $\left(\alpha-q_{C S R}-\gamma q_{P M}-c\right) q_{C S R}$ means the profits of the CSR firm. The second term $\frac{\mu}{2}\left(q_{C S R}^{2}+q_{P M}^{2}+2 \gamma q_{P M} q_{C S R}\right)$ implies the CSR firm's social concerns. The last term $-\beta q_{C S R}$ indicates the CSR firm's environmental responsibility.

For the profit maximizing firm, this firm maximizes the following profits (Eq. 4)

$$
\pi_{P M}=\left(\alpha-q_{P M}-\gamma q_{C S R}-c\right) q_{P M} .
$$

This paper further assumes that $\alpha>>\max \{\beta, c\}$ such that the market size is large enough.

\section{The primary conclusions}

The models of Eq. 1-4 are analyzed in this section. Eq. 3 and Eq.4 are all concave and there exists a unique solution. The equilibrium is determined by its first order conditions (Eq. 5 and 6). 


$$
\begin{aligned}
& \frac{\partial V_{C S R}}{\partial q_{C S R}}=\left(\alpha-2 q_{C S R}-\gamma q_{P M}-c\right)+\mu q_{C S R}+\gamma \mu q_{P M}-\beta=0 . \\
& \frac{\partial \pi_{P M}}{\partial q_{P M}}=\alpha-2 q_{P M}-\gamma q_{C S R}-c=0 .
\end{aligned}
$$

The equilibrium $q^{*}=\left(q_{C S R}^{*}, q_{P M}^{*}\right)$ is presented as follows (Eq. 7)

$$
\left(q_{C S R}^{*}, q_{P M}^{*}\right)=\left(\frac{2(\alpha-c-\beta)-\gamma(1-\mu)(\alpha-c)}{4-2 \mu-\gamma^{2}(1-\mu)}, \frac{(2-\mu)(\alpha-c)-\gamma(\alpha-c-\beta)}{4-2 \mu-\gamma^{2}(1-\mu)}\right) .
$$

The corresponding price is denoted to be $\left(p_{C S R}^{*}, p_{P M}^{*}\right)$. The corresponding objective functions are (Eq. 8)

$$
\begin{aligned}
& \left(V_{C S R}^{*}, \pi_{P M}^{*}\right)=\left(\left(1-\frac{\mu}{2}\right)\left[\frac{2(\alpha-c-\beta)-\gamma(1-\mu)(\alpha-c)}{4-2 \mu-\gamma^{2}(1-\mu)}\right]^{2}+\frac{\mu}{2}\left[\frac{(2-\mu)(\alpha-c)-\gamma(\alpha-c-\beta)}{4-2 \mu-\gamma^{2}(1-\mu)}\right]^{2},\right. \\
& \left.\left[\frac{(2-\mu)(\alpha-c)-\gamma(\alpha-c-\beta)}{4-2 \mu-\gamma^{2}(1-\mu)}\right]^{2}\right) .
\end{aligned}
$$

The corresponding profits of the CSR firm $\pi_{C S R}^{*}$ are denoted Eq.9

$$
\begin{aligned}
& \pi_{C S R}^{*}=(1-\mu)\left[\frac{2(\alpha-c-\beta)-\gamma(1-\mu)(\alpha-c)}{4-2 \mu-\gamma^{2}(1-\mu)}\right]^{2}+ \\
& \left\{\beta-\gamma \mu\left[\frac{(2-\mu)(\alpha-c)-\gamma(\alpha-c-\beta)}{4-2 \mu-\gamma^{2}(1-\mu)}\right]\right\}\left[\frac{2(\alpha-c-\beta)-\gamma(1-\mu)(\alpha-c)}{4-2 \mu-\gamma^{2}(1-\mu)}\right] .
\end{aligned}
$$

Here the solution is analyzed. Social concerns, environmental responsibility and product substitutability all have effects on the equilibrium and the values of the objective functions.

\subsection{Effects of social concerns}

By the comparative static analysis, for the equilibrium condition Eq.7, the following relationships are achieved.

$$
\frac{\partial q_{C S R}^{*}}{\partial \mu}=\frac{\gamma(\alpha-c)}{4-2 \mu-\gamma^{2}(1-\mu)} \quad+\left(2-\gamma^{2}\right) \frac{2(\alpha-c-\beta)-\gamma(1-\mu)(\alpha-c)}{\left[4-2 \mu-\gamma^{2}(1-\mu)\right]^{2}}>0, \quad \frac{\partial q_{P M}^{*}}{\partial \mu}=\frac{-(\alpha-c)}{4-2 \mu-\gamma^{2}(1-\mu)}+
$$




$$
\begin{aligned}
& \left(2-\gamma^{2}\right) \frac{(2-\mu)(\alpha-c)-\gamma(\alpha-c-\beta)}{\left[4-2 \mu-\gamma^{2}(1-\mu)\right]^{2}}= \\
& \frac{\partial\left(q_{C S R}^{*}+q_{P M}^{*}\right)}{\partial \mu}=\frac{(2-\gamma)\left(2-\gamma^{2}\right)(\alpha-c-\beta)-\gamma(\gamma-2)(\alpha-c)}{\left[4-2 \mu-\gamma^{2}(1-\mu)\right]^{2}}>0 .
\end{aligned}
$$

The price owns the following properties

$$
\begin{aligned}
& \frac{\partial p_{C S R}^{*}}{\partial \mu}=-\frac{\partial q_{C S R}^{*}}{\partial \mu}-\gamma \frac{\partial q_{P M}^{*}}{\partial \mu}=-\gamma \frac{\partial\left(q_{C S R}^{*}+q_{P M}^{*}\right)}{\partial \mu}-(1-\gamma) \frac{\partial q_{C S R}^{*}}{\partial \mu}<0 \quad \text { and } \quad \frac{\partial p_{P M}^{*}}{\partial \mu}=\quad-\frac{\partial q_{P M}^{*}}{\partial \mu}-\gamma \frac{\partial q_{C S R}^{*}}{\partial \mu} \\
& =-\frac{\gamma(\alpha-c)}{4-2 \mu-\gamma^{2}(1-\mu)}-\left(2-\gamma^{2}\right) \frac{2(\alpha-c-\beta)-\gamma(1-\mu)(\alpha-c)}{\left[4-2 \mu-\gamma^{2}(1-\mu)\right]^{2}}-\gamma \frac{-\gamma^{2}(\alpha-c)-\gamma\left(2-\gamma^{2}\right)(\alpha-c-\beta)}{\left[4-2 \mu-\gamma^{2}(1-\mu)\right]^{2}} \\
& \frac{-\left(2-\gamma^{2}\right)^{2}(\alpha-c-\beta)-\gamma\left(2-\gamma^{2}\right)(\alpha-c)}{\left[4-2 \mu-\gamma^{2}(1-\mu)\right]^{2}}<0 .
\end{aligned}
$$

The above analyses are summarized as follows:

Proposition 1: Social concerns increase both the CSR firms' and the total outputs but decrease the PM firms' outputs. Moreover, social concerns decrease the price of both types of firms.

Remarks: Social concerns stimulate the CSR firm to produce more while deterring the PM firm's outputs. The stimulating effects on the CSR firm are lager than the deterring effects on the PM firm. Since the stimulating effects on the CSR firm are larger than the deterring effects on the PM firm, social concerns decrease the prices of both firms. This is also consistent with the real-world phenomena in Flammer (2015b). With two databases: RiskMetrics and SharkRepellent, Flammer (2015b) found that CSR proposals are associated with an increase in labor productivity and sales growth.

The effects of the social concerns on the objective functions and the profits are further considered. Envelope theorem indicates Eq.10 and Eq.11. 


$$
\begin{aligned}
& \frac{\partial V_{C S R}^{*}}{\partial \mu}=-\frac{1}{2}\left[\frac{2(\alpha-c-\beta)-\gamma(1-\mu)(\alpha-c)}{4-2 \mu-\gamma^{2}(1-\mu)}\right]^{2}+\frac{1}{2}\left[\frac{(2-\mu)(\alpha-c)-\gamma(\alpha-c-\beta)}{4-2 \mu-\gamma^{2}(1-\mu)}\right]^{2}+ \\
& (2-\mu)\left[\frac{2(\alpha-c-\beta)-\gamma(1-\mu)(\alpha-c)}{4-2 \mu-\gamma^{2}(1-\mu)}\right] \frac{\partial q_{C S R}^{*}}{\partial \mu}+\mu\left[\frac{(2-\mu)(\alpha-c)-\gamma(\alpha-c-\beta)}{4-2 \mu-\gamma^{2}(1-\mu)}\right] \frac{\partial q_{M P}^{*}}{\partial \mu}, \\
& \frac{\partial \pi_{P M}}{\partial \mu}=2 q_{P M}^{*} \frac{\partial q_{P M}^{*}}{\partial \mu}, \\
& \frac{\partial \pi_{C S R}^{*}}{\partial \mu}=-\left[\frac{2(\alpha-c-\beta)-\gamma(1-\mu)(\alpha-c)}{4-2 \mu-\gamma^{2}(1-\mu)}\right]^{2}+2(1-\mu)\left[\frac{2(\alpha-c-\beta)-\gamma(1-\mu)(\alpha-c)}{4-2 \mu-\gamma^{2}(1-\mu)}\right] \frac{\partial q_{C S R}^{*}}{\partial \mu} \\
& \left\{-\gamma\left[\frac{(2-\mu)(\alpha-c)-\gamma(\alpha-c-\beta)}{4-2 \mu-\gamma^{2}(1-\mu)}\right]-\gamma \mu \frac{\partial q_{P M}^{*}}{\partial \mu}\right\}\left[\frac{2(\alpha-c-\beta)-\gamma(1-\mu)(\alpha-c)}{4-2 \mu-\gamma^{2}(1-\mu)}\right] \\
& +\left\{\beta-\gamma \mu\left[\frac{(2-\mu)(\alpha-c)-\gamma(\alpha-c-\beta)}{4-2 \mu-\gamma^{2}(1-\mu)}\right]\right\} \frac{\partial q_{C S R}^{*}}{\partial \mu} .
\end{aligned}
$$

Eq.10-Eq.12 imply

Proposition 2: Social concerns of the CSR firm reduce the profits of the PM firm. The value of the CSR firm's objective function increases with social concerns.

Proof. See in Appendix.

Remarks: The PM firm makes a loss because social concerns stimulate the CSR firm's outputs. Social concerns promote the objective function value of the CSR firm. The above results support empirical evidence in Flammer (2015b). Flammer (2015b) found that the adoption of CSR proposals leads to positive announcement returns.

For the profit of the CSR firm, the effects of social concerns are uncertain and the following example illustrates this phenomenon.

Example 1: For the profits of the CSR firm, Eq. 12 indicates 


$$
\begin{aligned}
& \frac{\partial \pi_{C S R}^{*}}{\partial \mu}=-\left[\frac{2(\alpha-c-\beta)-\gamma(1-\mu)(\alpha-c)}{4-2 \mu-\gamma^{2}(1-\mu)}\right]^{2} \\
& +2(1-\mu)\left[\frac{2(\alpha-c-\beta)-\gamma(1-\mu)(\alpha-c)}{4-2 \mu-\gamma^{2}(1-\mu)}\right] \frac{2\left(2-\gamma^{2}\right)(\alpha-c-\beta)+2 \gamma(\alpha-c)}{\left[4-2 \mu-\gamma^{2}(1-\mu)\right]^{2}}+ \\
& \left\{-\gamma\left[\frac{(2-\mu)(\alpha-c)-\gamma(\alpha-c-\beta)}{4-2 \mu-\gamma^{2}(1-\mu)}\right]-\gamma \mu \frac{\gamma^{2}(\alpha-c)+\gamma\left(2-\gamma^{2}\right)(\alpha-c-\beta)}{\left[4-2 \mu-\gamma^{2}(1-\mu)\right]^{2}}\right\}\left[\frac{2(\alpha-c-\beta)-\gamma(1-\mu)(\alpha-c)}{4-2 \mu-\gamma^{2}(1-\mu)}\right] \\
& +\left\{\beta-\gamma \mu\left[\frac{(2-\mu)(\alpha-c)-\gamma(\alpha-c-\beta)}{4-2 \mu-\gamma^{2}(1-\mu)}\right]\right\} \frac{2\left(2-\gamma^{2}\right)(\alpha-c-\beta)+2 \gamma(\alpha-c)}{\left[4-2 \mu-\gamma^{2}(1-\mu)\right]^{2}} \\
& =\frac{1}{\left[4-2 \mu-\gamma^{2}(1-\mu)\right]^{3}}\left\{-[2(\alpha-c-\beta)-\gamma(1-\mu)(\alpha-c)]^{2}\left[4-2 \mu-\gamma^{2}(1-\mu)\right]\right. \\
& +4(1-\mu)[2(\alpha-c-\beta)-\gamma(1-\mu)(\alpha-c)]\left[\left(2-\gamma^{2}\right)(\alpha-c-\beta)+2 \gamma(\alpha-c)\right] \\
& -\left\{\gamma[(2-\mu)(\alpha-c)-\gamma(\alpha-c-\beta)]\left[4-2 \mu-\gamma^{2}(1-\mu)\right]\right. \\
& \left.+\left(\gamma^{2} \mu+2 \gamma \mu\right)\left[\gamma(\alpha-c)+\left(2-\gamma^{2}\right)(\alpha-c-\beta)\right]\right\}[2(\alpha-c-\beta)-\gamma(1-\mu)(\alpha-c)] \\
& \left.+2 \beta\left[\left(2-\gamma^{2}\right)(\alpha-c-\beta)+\gamma(\alpha-c)\right]\left[4-2 \mu-\gamma^{2}(1-\mu)\right]\right\} . \\
& \left.\frac{\partial \pi_{C S R}^{*} \mid}{\partial \mu}\right|_{\gamma=1, \beta=0}=\frac{a-c}{(3-\mu)^{3}}\left\{-(3-\mu)(1+\mu)^{2}(\alpha-c)+12(1-\mu)(1+\mu)(\alpha-c)\right. \\
& -(1-\mu)(1+\mu)(3-\mu)(\alpha-c)-6 \mu(1+\mu)(\alpha-c)\} \\
& =\frac{a-c}{(3-\mu)^{3}}[12(1-\mu)(1+\mu)(\alpha-c)-2(1+\mu)(3-\mu)(\alpha-c)-6 \mu(1+\mu)(\alpha-c)] \\
& =\frac{(1+\mu)(a-c)^{2}}{(3-\mu)^{3}}(6-16 \mu) . \\
& \\
& +(\alpha)
\end{aligned}
$$

Therefore, $\left.\frac{\partial \pi_{C S R}^{*}}{\partial \mu}\right|_{\gamma=1, \beta=0}>0$ if $\mu<\frac{3}{8}$ and $\left.\quad \frac{\partial \pi_{C S R}^{*}}{\partial \mu}\right|_{\gamma=1, \beta=0} ^{<0}$ if $\mu>\frac{3}{8}$. The effects of social concerns on the profit of the CSR firm are uncertain.

\subsection{Environmental responsibility effects}

Here the environmental responsibility effects are further addressed with comparative static analysis. Eq.7 yields $\quad \frac{\partial q_{C S R}^{*}}{\partial \beta}=\frac{-2}{4-2 \mu-\gamma^{2}(1-\mu)}<0, \quad \frac{\partial q_{P M}^{*}}{\partial \beta}=\frac{\gamma}{4-2 \mu-\gamma^{2}(1-\mu)}>0 \quad$ and $\frac{\partial\left(q_{C S R}^{*}+q_{P M}^{*}\right)}{\partial \beta}=\frac{\gamma-2}{4-2 \mu-\gamma^{2}(1-\mu)}<0$

Moreover, for the prices of the two firms, the following properties are obtained. 
$\frac{\partial p_{C S R}^{*}}{\partial \beta}=-\frac{\partial q_{C S R}^{*}}{\partial \beta}-\gamma \frac{\partial q_{P M}^{*}}{\partial \beta}=\frac{2-\gamma^{2}}{4-2 \mu-\gamma^{2}(1-\mu)}>0$ and $\frac{\partial p_{P M}^{*}}{\partial \beta}=\frac{\gamma}{4-2 \mu-\gamma^{2}(1-\mu)}>0$. This is summarized as follows

Proposition 3: The environmental responsibility effect on the outputs of the PM firm is positive while environmental responsibility has negative effects on the CSR firm's outputs. The effects of environmental responsibility on the total outputs are also negative. Further, environmental responsibility improves the prices of both the firms' products.

Remarks: Because the CSR firm cares about the environment and the outputs are negatively related to environment externality, environment responsibility has deterring effects on the outputs of the CSR firm and the total outputs, while it has stimulating effects on the outputs of the PM firm. Moreover, since environment responsibility has deterring effects on the total outputs, the total emission is reduced by the environmental responsibility. Correspondingly, the prices of the two firms' products are increased with the environmental responsibility. Interestingly, the relationship $\gamma \frac{\partial q_{C S R}^{*}}{\partial \beta}+2 \frac{\partial q_{P M}^{*}}{\partial \beta}=0$ holds. Or the sum of the weighted environmental responsibility effects of the outputs is exact zero.

The effects of the environment responsibility on the objective functions are further analyzed.

$$
\begin{aligned}
& \frac{\partial V_{C S R}^{*}}{\partial \beta}=\left[\frac{2(\alpha-c-\beta)-\gamma(1-\mu)(\alpha-c)}{4-2 \mu-\gamma^{2}(1-\mu)}\right] \frac{-4+2 \mu}{4-2 \mu-\gamma^{2}(1-\mu)} \\
& +\left[\frac{(2-\mu)(\alpha-c)-\gamma(\alpha-c-\beta)}{4-2 \mu-\gamma^{2}(1-\mu)}\right] \frac{\gamma \mu}{4-2 \mu-\gamma^{2}(1-\mu)} \\
& =-\frac{(\alpha-c-\beta)\left(8-4 \mu+\gamma^{2} \mu\right)-(\alpha-c) \gamma(2-\mu)(2-\mu)}{\left[4-2 \mu-\gamma^{2}(1-\mu)\right]^{2}}
\end{aligned}
$$




$$
\begin{aligned}
& \frac{\partial \pi_{P M}}{\partial \beta}=2 q_{P M}^{*} \frac{\partial q_{P M}^{*}}{\partial \beta}, \\
& \frac{\partial \pi_{C S R}^{*}}{\partial \beta}=-\left[\frac{2(\alpha-c-\beta)-\gamma(1-\mu)(\alpha-c)}{4-2 \mu-\gamma^{2}(1-\mu)}\right] \frac{4(1-\mu)}{4-2 \mu-\gamma^{2}(1-\mu)}+ \\
& \left(1-\frac{\gamma^{2} \mu}{4-2 \mu-\gamma^{2}(1-\mu)}\right)\left[\frac{2(\alpha-c-\beta)-\gamma(1-\mu)(\alpha-c)}{4-2 \mu-\gamma^{2}(1-\mu)}\right] \\
& -\left\{\beta-\gamma \mu\left[\frac{(2-\mu)(\alpha-c)-\gamma(\alpha-c-\beta)}{4-2 \mu-\gamma^{2}(1-\mu)}\right]\right\} \frac{2}{4-2 \mu-\gamma^{2}(1-\mu)} .
\end{aligned}
$$

Based on Eq. 13-15, the following conclusions hold

Proposition 4: Environmental responsibility of the CSR firm increases the profits of the PM firm, while decreases the value of the CSR firm's objective functions.

Proof. See in Appendix.

Remarks: The effects of environmental responsibility on firms' objective functions and profits are all addressed. The PM firm benefits from the CSR firm's environmental responsibility while the CSR firm's objective function value is reduced by its environmental responsibility. Conclusions in Proposition 3-4 are consistent with empirical results in Flammer (2013). Flammer (2013) identified that companies reported to behave responsibly toward the environment experience a significant stock price increase, whereas firms that behave irresponsibly face a significant decrease. Flammer (2013) thought that the positive (negative) stock market reaction to eco-friendly (-harmful) events is smaller for companies with higher levels of environmental CSR. In summary, conclusions in Proposition 3-4 are highly fit with the ideas in Flammer (2013) and this article shows the results of Flammer (2013) with theoretical model.

Moreover, the effects of environmental responsibility on the profits of the CSR firm seem uncertain, which depend on social concerns and product substitutability. Here an example is presented to describe this fact. 
Example 2. Eq.9 indicates

$$
\begin{aligned}
& \frac{\partial \pi_{C S R}^{*}}{\partial \beta}=\left[\frac{2(\alpha-c-\beta)-\gamma(1-\mu)(\alpha-c)}{4-2 \mu-\gamma^{2}(1-\mu)}\right] \frac{2 \mu-\gamma^{2}}{4-2 \mu-\gamma^{2}(1-\mu)} \\
& -\left\{\beta-\gamma \mu\left[\frac{(2-\mu)(\alpha-c)-\gamma(\alpha-c-\beta)}{4-2 \mu-\gamma^{2}(1-\mu)}\right]\right\} \frac{2}{4-2 \mu-\gamma^{2}(1-\mu)} \\
& =\frac{1}{4-2 \mu-\gamma^{2}(1-\mu)}\left\{\frac{\left(4 \mu-2 \gamma^{2}-2 \gamma^{2} \mu\right)(\alpha-c-\beta)+\gamma\left(2 \mu+\gamma^{2}-\mu \gamma^{2}\right)(\alpha-c)}{4-2 \mu-\gamma^{2}(1-\mu)}-2 \beta\right] .
\end{aligned}
$$

Thus, $\left.\frac{\partial \pi_{C S R}^{*}}{\partial \beta}\right|_{\mu=0, \gamma>0}<0$ and $\left.\frac{\partial \pi_{C S R}^{*}}{\partial \beta}\right|_{\gamma=0, \mu>0}>0$. Therefore, the effects of environmental responsibility on the profits of the CSR firm are uncertain.

\subsection{Product substitutability effects}

The effects of the product substitutability are considered here. Comparative static analysis implies

$$
\begin{aligned}
& \frac{\partial q_{C S R}^{*}}{\partial \gamma}=\frac{-(1-\mu)(\alpha-c)}{4-2 \mu-\gamma^{2}(1-\mu)}+(1-\mu) \frac{2(\alpha-c-\beta)-\gamma(1-\mu)(\alpha-c)}{\left[4-2 \mu-\gamma^{2}(1-\mu)\right]^{2}} \\
& =(1-\mu) \frac{2(\alpha-c-\beta)-\left[\gamma(1-\mu)+4-2 \mu-\gamma^{2}(1-\mu)\right](\alpha-c)}{\left[4-2 \mu-\gamma^{2}(1-\mu)\right]^{2}}, \\
& =(1-\mu) \frac{-2 \beta-\left[\gamma(1-\mu)+2-2 \mu-\gamma^{2}(1-\mu)\right](\alpha-c)}{\left[4-2 \mu-\gamma^{2}(1-\mu)\right]^{2}}<0
\end{aligned}
$$

$$
\begin{aligned}
& \frac{\partial q_{P M}^{*}}{\partial \gamma}=\frac{-(\alpha-c-\beta)}{4-2 \mu-\gamma^{2}(1-\mu)}+(1-\mu) \frac{(2-\mu)(\alpha-c)-\gamma(\alpha-c-\beta)}{\left[4-2 \mu-\gamma^{2}(1-\mu)\right]^{2}} \\
& =\frac{(2-\mu)(1-\mu)(\alpha-c)-\left[\gamma(1-\mu)+4-2 \mu-\gamma^{2}(1-\mu)\right](\alpha-c-\beta)}{\left[4-2 \mu-\gamma^{2}(1-\mu)\right]^{2}}<0 .
\end{aligned}
$$

The above inequality comes from the hypothesis of $\alpha>>\max \{\beta, c\}$. Moreover, $\frac{\partial p_{C S R}^{*}}{\partial \gamma}>0$ and 
$\frac{\partial p_{P M}^{*}}{\partial \gamma}>0$

Proposition 5: The outputs of both the CSR firm and the PM one decrease with product substitutability while the prices increase with product substitutability.

Remarks: The low product substitutability improves the market power of the two firms and the outputs of both firms decrease while the prices increase. In this case, low product substitutability weakens competition in this industry.

The effects of the product substitutability on the objective functions are considered and Eq. 16-18 are achieved.

$\frac{\partial V_{C S R}^{*}}{\partial \gamma}=(2-\mu)\left[\frac{2(\alpha-c-\beta)-\gamma(1-\mu)(\alpha-c)}{4-2 \mu-\gamma^{2}(1-\mu)}\right] \frac{\partial q_{C S R}^{*}}{\partial \gamma}+\mu\left[\frac{(2-\mu)(\alpha-c)-\gamma(\alpha-c-\beta)}{4-2 \mu-\gamma^{2}(1-\mu)}\right] \frac{\partial q_{P M}^{*}}{\partial \gamma}<0$,

$\frac{\partial \pi_{P M}^{*}}{\partial \gamma}=2\left[\frac{(2-\mu)(\alpha-c)-\gamma(\alpha-c-\beta)}{4-2 \mu-\gamma^{2}(1-\mu)}\right] \frac{\partial q_{P M}^{*}}{\partial \gamma}<0$

$$
\begin{aligned}
& \frac{\partial \pi_{C S R}^{*}}{\partial \gamma}=2(1-\mu)\left[\frac{2(\alpha-c-\beta)-\gamma(1-\mu)(\alpha-c)}{4-2 \mu-\gamma^{2}(1-\mu)}\right] \frac{\partial q_{C S R}^{*}}{\partial \gamma}+\left\{\beta-\gamma \mu\left[\frac{(2-\mu)(\alpha-c)-\gamma(\alpha-c-\beta)}{4-2 \mu-\gamma^{2}(1-\mu)}\right]\right\} \frac{\partial q_{P M}^{*}}{\partial \gamma} \\
& -\left\{\gamma \mu \frac{\partial q_{P M}^{*}}{\partial \gamma}+\mu\left[\frac{(2-\mu)(\alpha-c)-\gamma(\alpha-c-\beta)}{4-2 \mu-\gamma^{2}(1-\mu)}\right]\right\}\left[\frac{2(\alpha-c-\beta)-\gamma(1-\mu)(\alpha-c)}{4-2 \mu-\gamma^{2}(1-\mu)}\right] .
\end{aligned}
$$

Proposition 6: Higher product substitutability yields lower profits for the PM firm and lower value of the CSR firm's objective function.

Remarks: Higher product substitutability means fiercer competition, which yields lower profits for the PM firm and lower value of the CSR firm's objective function. Kitzmueller \& Shimshack (2012) pointed out that product substitutability affects firms' optimal CSR. Actually, CSR reduces product substitutability. According to Besley \& Ghatak (2007), there is also widespread evidence 
that customers care about CSR when choosing where to shop. For example MORI find that $70 \%$ of consumers are willing to pay more for a product which they perceive as ethically superior. Fairtrade brands such as Cafedirect command 5\% of the UK market for ground coffee. Therefore, Proposition 5-6 are consistent with conclusions in Kitzmueller \& Shimshack (2012) and Besley \& Ghatak(2007).

Moreover, the effects of the product substitutability on the profits of the CSR firm also seem uncertain. For example, $\left.\frac{\partial \pi_{C S R}^{*}}{\partial \gamma}\right|_{\mu=0}<0$ while $\left.\frac{\partial \pi_{C S R}^{*}}{\partial \gamma}\right|_{\mu=1, \beta=0}>0$ if $\gamma>\frac{1}{2}$.

\section{Further discussion}

Here the effects of the CSR on the two firms' profits are analyzed. Without CSR, the two firms' profits are $\bar{\pi}_{1}(\beta=0 ; \mu=0)=\bar{\pi}_{2}(\beta=0 ; \mu=0)=\left[\frac{(\alpha-c)}{2+\gamma}\right]^{2}$.

Compared with Eq. 9, Eq.19 and Eq.20 hold.

$$
\begin{aligned}
& \pi_{C S R}^{*}(\mu=0)-\bar{\pi}_{2}(\beta=0 ; \mu=0)=\left[\frac{2(\alpha-c-\beta)-\gamma(\alpha-c)}{4-\gamma^{2}}\right]^{2}+\beta\left[\frac{2(\alpha-c-\beta)-\gamma(\alpha-c)}{4-\gamma^{2}}\right]-\left[\frac{(\alpha-c)}{2+\gamma}\right]^{2} \\
& =\left[\frac{2 \beta}{4-\gamma^{2}}\right]^{2}-\frac{2 \beta^{2}}{4-\gamma^{2}}-\frac{4 \beta}{4-\gamma^{2}}\left[\frac{2(\alpha-c)-\gamma(\alpha-c)}{4-\gamma^{2}}\right]+\beta\left[\frac{2(\alpha-c)-\gamma(\alpha-c)}{4-\gamma^{2}}\right] \\
& =-\frac{2 \beta^{2}}{4-\gamma^{2}} \frac{2-\gamma^{2}}{4-\gamma^{2}}-\frac{\gamma^{2} \beta}{4-\gamma^{2}}\left[\frac{2(\alpha-c)-\gamma(\alpha-c)}{4-\gamma^{2}}\right] \leq 0 . \\
& \pi_{P M}^{*}(\mu=0)-\bar{\pi}_{1}(\beta=0 ; \mu=0)=\left[\frac{2(\alpha-c)-\gamma(\alpha-c-\beta)}{4-\gamma^{2}}\right]^{2}-\left[\frac{(\alpha-c)}{2+\gamma}\right]^{2} \\
& =\left[\frac{(\alpha-c)}{2+\gamma}+\frac{\gamma \beta}{4-\gamma^{2}}\right]^{2}-\left[\frac{(\alpha-c)}{2+\gamma}\right]^{2} \geq 0 .
\end{aligned}
$$

That is, without social concerns, environmental responsibility reduces the profits of the CSR firm but the PM firm benefits from the CSR firm's environmental responsibility.

Proposition 7: $\pi_{C S R}^{*}(\mu=0) \leq \bar{\pi}_{2}(\beta=0 ; \mu=0)$ and $\pi_{P M}^{*}(\mu=0) \geq \bar{\pi}_{1}(\beta=0 ; \mu=0)$. The inequalities 
strictly hold if $\beta>0$ for CSR firms.

Remarks: Without social concerns, environmental responsibility reduces the CSR firm's profits. In general, social responsibility improves the CSR firms' profits. The above conclusions are contrary to the traditional results (McWilliams et al., 2006) because environmental responsibility deters the two firms' outputs. An environmental CSR firm without social concerns tries to reduce emission. Thus, conclusions contrary to the traditional results (McWilliams et al., 2006) are achieved.

Without environmental responsibility, the profits of the CSR firm is addressed and Eq. 9 implies

$$
\begin{aligned}
& \pi_{C S R}^{*}(\beta=0)-\bar{\pi}_{2}(\beta=0 ; \mu=0)=(1-\mu)\left[\frac{2(\alpha-c)-\gamma(1-\mu)(\alpha-c)}{4-2 \mu-\gamma^{2}(1-\mu)}\right]^{2}- \\
& -\gamma \mu\left[\frac{(2-\mu)(\alpha-c)-\gamma(\alpha-c)}{4-2 \mu-\gamma^{2}(1-\mu)}\right]\left[\frac{2(\alpha-c)-\gamma(1-\mu)(\alpha-c)}{4-2 \mu-\gamma^{2}(1-\mu)}\right]-\left[\frac{(\alpha-c)}{2+\gamma}\right]^{2} \\
& =\frac{[2-\gamma(1-\mu)](\alpha-c)}{4-2 \mu-\gamma^{2}(1-\mu)} \frac{\left(2-2 \mu-\gamma+\gamma^{2} \mu\right)(\alpha-c)}{4-2 \mu-\gamma^{2}(1-\mu)}-\left[\frac{(\alpha-c)}{2+\gamma}\right]^{2} \\
& =\left\{\frac{\alpha-c}{\left[4-2 \mu-\gamma^{2}(1-\mu)\right](2+\gamma)}\right\}^{2}\left\{(2-\gamma+\gamma \mu)\left(2-2 \mu-\gamma+\gamma^{2} \mu\right)(2+\gamma)^{2}-\left[4-2 \mu-\gamma^{2}(1-\mu)\right]^{2}\right\} .
\end{aligned}
$$

$$
\begin{aligned}
& \pi_{C S R}^{*}(\beta=0)-\left.\bar{\pi}_{2}(\beta=0 ; \mu=0)\right|_{\gamma=0}=\left\{\frac{\alpha-c}{\left[4-2 \mu-\gamma^{2}(1-\mu)\right](2+\gamma)}\right\}^{2}\left(-4 \mu^{2}\right) \leq 0 . \\
& \pi_{C S R}^{*}(\beta=0)-\left.\bar{\pi}_{2}(\beta=0 ; \mu=0)\right|_{\gamma=1}=\left\{\frac{\alpha-c}{\left[4-2 \mu-\gamma^{2}(1-\mu)\right](2+\gamma)}\right\}^{2}\left(6 \mu-8 \mu^{2}\right) .
\end{aligned}
$$

The above analyses are summarized as follows

Proposition 8: Without environment responsibility, if the products are independent, CSR reduces the profits of the CSR firms; If the products are perfect substitutes, there exists a parameter $\mu^{*}$ where the CSR firm makes a loss under $\mu>\mu^{*}$ and earns a benefit under $\mu<\mu^{*}$. Therefore, $\mu^{*}=\frac{3}{4}$ 
Remarks: For independent products, both of the two firms are monopolists. Because the monopolist produces more than those under monopoly without CSR, CSR reduces the profits of the CSR firm.

Under perfect substitute, in general, the parameter $\mu$ is small and therefore socially concerned firm has a higher profit. This is consistent with the existing conclusions. This Proposition also considers large social concerns and presents the interesting conclusions. In summary, without environmental responsibility, under perfect substitute, small CSR improves the CSR firm's profits, while the conclusions are opposite under large CSR.

In general cases, the CSR firm also may benefit from CSR under certain conditions and CSR yields lower profits of the CSR firm under other conditions.

The above conclusions support the governmental decisions to subsidize firms' environmental responsibility and social concerns. The policy implication of Proposition 7 is to subsidize the environmental responsibility to reduce the emission. Furthermore, the policy implication is also to subsidize the social concerns to promote the consumer surplus (Nie, Yang, Chen and Wang, 2016; Nie, Wang and Yang, 2017).

\section{Concluding remarks}

This article investigates the effects of social concerns and environmental responsibility for the CSR firm and the PM firm. The effects of social concerns, environmental responsibility and product substitutability on the PM firm's profits and the CSR firm's objective function are all analyzed. The effects of social concerns, environmental responsibility and product substitutability on the CSR firm's profits are uncertain. Compared with social concerns, the environmental responsibility has opposite effects on the outputs, the price and the objective functions of the two firms.

The effects of CSR on firms' performance are also analyzed and the traditional conclusions may not hold because of the existence of environmental responsibility and product substitutability. Some further researching topics arise. On one hand, in practice, asymmetric information has crucial 
effects on firms' strategies and it is important to extend to asymmetric information situation. On the other hand, it is interesting to launch empirical research to test the above theory.

\section{Appendix}

\section{Proof of Proposition 2}

According to Eq. 8, $\frac{\partial q_{P M}^{*}}{\partial \mu}<0$ indicates $\frac{\partial \pi_{P M}}{\partial \mu}=2 q_{P M}^{*} \frac{\partial q_{P M}^{*}}{\partial \mu}<0$. Thus, social concerns of the

CSR firm reduce the profits of the PM firm. For the objective function of the CSR firm Eq. 8, the following formulation holds

$$
\begin{aligned}
& \frac{\partial V_{C S R}^{*}}{\partial \mu}=-\frac{1}{2}\left[\frac{2(\alpha-c-\beta)-\gamma(1-\mu)(\alpha-c)}{4-2 \mu-\gamma^{2}(1-\mu)}\right]^{2}+\frac{1}{2}\left[\frac{(2-\mu)(\alpha-c)-\gamma(\alpha-c-\beta)}{4-2 \mu-\gamma^{2}(1-\mu)}\right]^{2}+ \\
& (2-\mu)\left[\frac{2(\alpha-c-\beta)-\gamma(1-\mu)(\alpha-c)}{4-2 \mu-\gamma^{2}(1-\mu)}\right] \frac{\partial q_{C S R}^{*}}{\partial \mu}+\mu\left[\frac{(2-\mu)(\alpha-c)-\gamma(\alpha-c-\beta)}{4-2 \mu-\gamma^{2}(1-\mu)}\right] \frac{\partial q_{M P}^{*}}{\partial \mu} \\
& =-\frac{1}{2}\left[\frac{2(\alpha-c-\beta)-\gamma(1-\mu)(\alpha-c)}{4-2 \mu-\gamma^{2}(1-\mu)}\right]^{2}+\frac{1}{2}\left[\frac{(2-\mu)(\alpha-c)-\gamma(\alpha-c-\beta)}{4-2 \mu-\gamma^{2}(1-\mu)}\right]^{2}+ \\
& (2-\mu)\left[\frac{2(\alpha-c-\beta)-\gamma(1-\mu)(\alpha-c)}{4-2 \mu-\gamma^{2}(1-\mu)}\right] \frac{2\left(2-\gamma^{2}\right)(\alpha-c-\beta)+2 \gamma(\alpha-c)}{\left[4-2 \mu-\gamma^{2}(1-\mu)\right]^{2}} \\
& -\mu\left[\frac{(2-\mu)(\alpha-c)-\gamma(\alpha-c-\beta)}{4-2 \mu-\gamma^{2}(1-\mu)}\right] \frac{\gamma^{2}(\alpha-c)+\gamma\left(2-\gamma^{2}\right)(\alpha-c-\beta)}{\left[4-2 \mu-\gamma^{2}(1-\mu)\right]^{2}} \\
& =-\frac{1}{2}\left[\frac{(2-\gamma+\gamma \mu)(\alpha-c)-2 \beta}{4-2 \mu-\gamma^{2}(1-\mu)}\right]^{2}+\frac{1}{2}\left[\frac{(2-\mu-\gamma)(\alpha-c)+\gamma \beta}{4-2 \mu-\gamma^{2}(1-\mu)}\right]^{2}+ \\
& (2-\mu) \frac{(2-\gamma+\gamma \mu)(\alpha-c)-2 \beta}{4-2 \mu-\gamma^{2}(1-\mu)} \frac{2\left(2-\gamma^{2}+\gamma\right)(\alpha-c)-2\left(2-\gamma^{2}\right) \beta}{\left[4-2 \mu-\gamma^{2}(1-\mu)\right]^{2}} \\
& -\mu \gamma\left[\frac{(2-\mu-\gamma)(\alpha-c)+\gamma \beta}{4-2 \mu-\gamma^{2}(1-\mu)}\right] \frac{\left(\gamma+2-\gamma^{2}\right)(\alpha-c)-\left(2-\gamma^{2}\right) \beta}{\left[4-2 \mu-\gamma^{2}(1-\mu)\right]^{2}} \\
& =\frac{1}{2\left[4-2 \mu-\gamma^{2}(1-\mu)\right]^{3}}\left\{\left[4-2 \mu-\gamma^{2}(1-\mu)\right][(2-\mu-\gamma)(\alpha-c)+\gamma \beta]^{2}\right. \\
& -\left[4-2 \mu-\gamma^{2}(1-\mu)\right][(2-\gamma+\gamma \mu)(\alpha-c)-2 \beta]^{2} \\
& +2(4-2 \mu)[(2-\gamma+\gamma \mu)(\alpha-c)-2 \beta]\left[\left(2+\gamma-\gamma^{2}\right)(\alpha-c)-\left(2-\gamma^{2}\right) \beta\right] \\
& \left.-2 \mu \gamma[(2-\mu-\gamma)(\alpha-c)+\gamma \beta]\left[\left(2+\gamma-\gamma^{2}\right)(\alpha-c)-\left(2-\gamma^{2}\right) \beta\right]\right\}
\end{aligned}
$$


$=\frac{1}{2\left[4-2 \mu-\gamma^{2}(1-\mu)\right]^{3}}\left\{\left[4-2 \mu-\gamma^{2}(1-\mu)\right][(2-\mu-\gamma)(\alpha-c)+\gamma \beta]^{2}\right.$

$+(4-2 \mu)[(2-\gamma+\gamma \mu)(\alpha-c)-2 \beta]\left[\left(2+\gamma-\gamma^{2}\right)(\alpha-c)-\left(2-\gamma^{2}\right) \beta\right]$

$-\left[4-2 \mu-\gamma^{2}(1-\mu)\right][(2-\gamma+\gamma \mu)(\alpha-c)-2 \beta]^{2}$

$+(4-2 \mu)[(2-\gamma+\gamma \mu)(\alpha-c)-2 \beta]\left[\left(2+\gamma-\gamma^{2}\right)(\alpha-c)-\left(2-\gamma^{2}\right) \beta\right]$

$\left.-2 \mu \gamma[(2-\mu-\gamma)(\alpha-c)+\gamma \beta]\left[\left(2+\gamma-\gamma^{2}\right)(\alpha-c)-\left(2-\gamma^{2}\right) \beta\right]\right\}>0$.

By $\gamma, \mu \in[0,1],\left(2+\gamma-\gamma^{2}\right)(\alpha-c)-\left(2-\gamma^{2}\right) \beta>(2-\gamma+\gamma \mu)(\alpha-c)-2 \beta$ and $4-2 \mu>4-2 \mu-\gamma^{2}(1-\mu)$ imply the relationship

$(4-2 \mu)[(2-\gamma+\gamma \mu)(\alpha-c)-2 \beta]\left[\left(2+\gamma-\gamma^{2}\right)(\alpha-c)-\left(2-\gamma^{2}\right) \beta\right]>$

$\left[4-2 \mu-\gamma^{2}(1-\mu)\right][(2-\gamma+\gamma \mu)(\alpha-c)-2 \beta]^{2}$.

The hypothesis $\alpha \gg \max \{\beta, c\}$ and the relationship $2-\gamma+\gamma \mu>2-\mu-\gamma$

yield $\quad(2-\gamma+\gamma \mu)(\alpha-c)-2 \beta>(2-\mu-\gamma)(\alpha-c)+\gamma \beta \quad$. Furthermore, $\quad \gamma, \mu \in[0,1]$, $(2-\gamma+\gamma \mu)(\alpha-c)-2 \beta>(2-\mu-\gamma)(\alpha-c)+\gamma \beta$ and $4-2 \mu>4-2 \mu-\gamma^{2}(1-\mu)$ jointly indicate the relationship

$(4-2 \mu)[(2-\gamma+\gamma \mu)(\alpha-c)-2 \beta]\left[\left(2+\gamma-\gamma^{2}\right)(\alpha-c)-\left(2-\gamma^{2}\right) \beta\right]>$

$2 \mu \gamma[(2-\mu-\gamma)(\alpha-c)+\gamma \beta]\left[\left(2+\gamma-\gamma^{2}\right)(\alpha-c)-\left(2-\gamma^{2}\right) \beta\right]$.

Therefore, the above inequality of Eq.A1 is achieved and $\frac{\partial V_{C S R}^{*}}{\partial \mu}>0$ holds correspondingly.

Conclusions are achieved and the proof is complete.

\section{Proof of Proposition 4}

By Eq.8, $\frac{\partial q_{P M}^{*}}{\partial \beta}>0$ yields $\frac{\partial \pi_{P M}}{\partial \beta}=2 q_{P M}^{*} \frac{\partial q_{P M}^{*}}{\partial \beta}>0$. Therefore, environmental responsibility of the CSR firm increases the profits of the PM firm. For the objective function of the CSR firm, Eq.14 implies

This article is protected by copyright. All rights reserved. 
$\frac{\partial V_{C S R}^{*}}{\partial \beta}=-\frac{(\alpha-c-\beta)\left(8-4 \mu+\gamma^{2} \mu\right)-(\alpha-c) \gamma(2-\mu)(2-\mu)}{\left[4-2 \mu-\gamma^{2}(1-\mu)\right]^{2}}<0$.

The above inequality comes from the hypothesis of $\alpha \gg \max \{\beta, c\}$. Thus, the environmental responsibility reduces the values of the CSR firm's objective function while increases the profits of the PM firm.

Conclusions are achieved and the proof is complete.

Declare This article does not contain any studies with human participants performed by any of the authors.

\section{References}

Baron D.P., (2008), Managerial contracting and corporate social responsibility, Journal of Public Economics, 92, 268-288.

Benabou R., Tirole J., (2010), Individual and corporate social responsibility, Economica, 77, 1-19.

Besley T., Ghatak M., (2007), Retailing public goods: the economics of corporate social responsibility, Journal of Public Economics, 91, 1645-63.

Brammer S., Millington A., (2008), Does it pay to be different? An analysis of the relationship between corporate social and financial performance, Strategic Management Journal, 29, $1325-1343$.

Carroll A.B., Shabana K.M., (2010), The business case for corporate social responsibility: a review of concepts, research and practice, International Journal of Management Reviews, 12, 85-105.

Chen, Y. H., Wen, X. W., \& Luo, M. Z. (2016). Corporate social responsibility spillover and competition effects on the food industry. Australian Economic Papers, 55(1), 1-13.

Chen, Y. H., \& Nie, P. Y. (2016). Duopoly competition in food industry considering corporate social responsibility. Quality Assurance and Safety of Crops \& Foods, 8(1), 33-40.

Chen, Y. H., Nie, P. Y., \& Yang, Y. C. (2017). Effects of corporate social responsibility on food 
safety. Agricultural Economics (Zemědělská Ekonomika), 63(12), 539-547.

Chen, Y. H., Wen, X. W., Wang, B., \& Nie, P. Y. (2017). Agricultural pollution and regulation: How to subsidize agriculture?. Journal of Cleaner Production, 164, 258-264.

Cheng, B., Ioannou, I., \& Serafeim, G. (2014). Corporate social responsibility and access to finance. Strategic Management Journal, 35(1), 1-23.

Fernandez-Kranz D., Santalo J., (2010), When necessity becomes a virtue: the effect of product competition on corporate social responsibility, Journal of Economics and Management Strategy, 19,453-487.

Fiksel, J., \& Lal, R. (2018). Transforming waste into resources for the Indian economy. Environmental Development. 26,123-128.

Flammer, C. (2015). Does product market competition foster corporate social responsibility?

Evidence from trade liberalization. Strategic Management Journal, 36(10), 1469-1485.

Flammer, C. (2013). Corporate social responsibility and shareholder reaction: The environmental awareness of investors. Academy of Management Journal, 56(3), 758-781.

Flammer, C. (2015b). Does corporate social responsibility lead to superior financial performance? A regression discontinuity approach. Management Science, 61(11), 2549-2568.

Flammer, C., \& Luo, J. (2017). Corporate social responsibility as an employee governance tool: Evidence from a quasi Sexperginebtanagement Journal, 38(2), 163-183.

Flammer, C. (2018). Competing for government procurement contracts: The role of corporate social responsibility. Strategic Management Journal, 39(5), 1299-1324.

Goering G.E., (2008), Welfare impacts of a non-profit firm in mixed commercial markets, Economic Systems, 32, 326-334.

Goering G.E., (2010), Corporate social responsibility, durable-goods and firm profitability, Managerial and Decision Economics, 31, 489-496.

Hillman A.J., Keim G.D., (2001), Shareholder value, stakeholder management, and social issues: what's the bottom line? Strategic Management Journal, 22, 125-139.

Kim, Y. (2017). Consumer responses to the food industry's proactive and passive environmental 
CSR, factoring in price as CSR tradeoff. Journal of Business Ethics, 140(2), 307-321.

Kitzmueller M., Shimshack J., (2012), Economic perspectives on corporate social responsibility, Journal of Economic Literature, 50, 51-84.

Kopel M., Brand B., (2012), Socially responsible firms and endogenous choice of strategic incentives, Economic Modelling, 29, 982-989.

Kopel M.,(2011), Strategic CSR, spillovers, and first-mover advantage, Working Paper. On line at: http://papers.ssrn.com/sol3/papers.cfm?abstract_id=1408632.

KPMG, (2008), International survey of Corporate Social Responsibility Reporting 2008. On line at: http://www.kpmg.com/EU/en/Documents/KPMG_International_survey_Corporate_responsibilit y_Survey_Reporting_2008.pdf .

Lambertini L., Tampieri A., (2010), Corporate social responsibility in a mixed oligopoly. Working Paper, No. 723. University of Bologna. On line at: http://papers.ssrn.com/sol3/papers.cfm?abstract_id=1729130.

Marin L., Rubio, A., Ruiz de Maya S., (2012), Competitiveness as a strategic outcome of corporate social responsibility, Corporate Social Responsibility and Environmental Management, 19, 364-376.

McWilliams A., Siegel D., Wright P.M.,(2006), Guest Editors Introduction-Corporate social responsibility: strategic implications, Journal of Management Studies, 43, 1-18.

Mohr L.A., Webb, D.J., Harris, K.E., (2001), Do consumers expect companies to be socially responsible? The impact of corporate social responsibility on buying behavior, The Journal of Consumer Affairs, 35, 45-72.

Nie P.Y., Chen Y.H., (2012), Duopoly competitions with capacity constrained input, Economic Modelling, 29,1715-1721.

Nie, P. Y. (2014). Effects of capacity constraints on mixed duopoly. Journal of Economics, 112(3), 283-294.

Nie, P. Y. (2018). Comparing horizontal mergers under Cournot with Bertrand competitions. Australian Economic Papers, 57(1), 55-80. 
Nie, P. Y., Yang, Y. C., Chen, Y. H., \& Wang, Z. H. (2016). How to subsidize energy efficiency under duopoly efficiently?. Applied Energy, 175, 31-39.

Nie, P. Y., Wang, C., \& Yang, Y. C. (2017). Comparison of energy efficiency subsidies under market power. Energy Policy, 110, 144-149.

Nie, P. Y., Wang, C., Chen, Z. Y., \& Chen, Y. H. (2018). A theoretic analysis of key person insurance. Economic Modelling, 71, 272-278.

Nie, P.Y., Wang, C., Chen, Y.H. \& Yang, Y.C. (2018) Effects of switching costs on innovative investment, Technological and Economic Development of Economy, 14(3), 933-949.

Nie, P. Y., Wang, C. \& Chen, Y. H. (2018). Top runner program in China: A theoretical analysis for potential subsidies, Energy Strategy Reviews, 21, 157-162.

Nie, P. Y., \& Wang, C. (2019). An analysis of cost-reduction innovation under capacity constrained inputs. Applied Economics, 51(6), 564-576. https://doi.org/10.1080/00036846.2018.1497850

Nishitani, K., Jannah, N., \& Kaneko, S. (2017). Does corporate environmental performance enhance financial performance? An empirical study of Indonesian firms. Environmental Development, 23, 10-21.

Orlitzky M., Schmidt F., Rynes, S., (2003), Corporate social and financial performance: a meta analysis, Organization Studies, 24, 403-441.

Schrempf J., (2012), The delimitation of corporate social responsibility: upstream, downstream, and historic CSR , Business \& Society, 51, 690-707 .

Starks L.T., (2009), Corporate governance and corporate social responsibility: what do investors care about? What should investors care about? The Financial Review, 44, 461-468.

Wang, C., \& Nie, P. Y. (2016). Effects of asymmetric medical insurance subsidy on hospitals competition under non-price regulation. International Journal for Equity in Health, 15(1), 184.

Wang, C., \& Nie, P. Y. (2018a). A note on effects of rational bubble on portfolios. Physica A: Statistical Mechanics and its Applications, 492, 50-56.

Wang, C., Nie, P.Y. \& Meng, Y. (2018) Duopoly competition with corporate social responsibility, Australian Economic Papers, 57(3), 327-345. 
Wang, C., \& Nie, P. Y. (2018b). How rebound effects of efficiency improvement and price jump of energy influence energy consumption?. Journal of Cleaner Production,202, 497-503.

Wang, H., Tong, L., Takeuchi, R., \& George, G. (2016). Corporate social responsibility: An overview and new research directions thematic issue on corporate social responsibility. Academy of Management Journal, 59(2), 534-544.

Yang, Y. C., Nie, P. Y., Liu, H. T., \& Shen, M. H. (2018). On the welfare effects of subsidy game for renewable energy investment: toward a dynamic equilibrium model. Renewable Energy, 121, 420-428. 


\section{University Library}

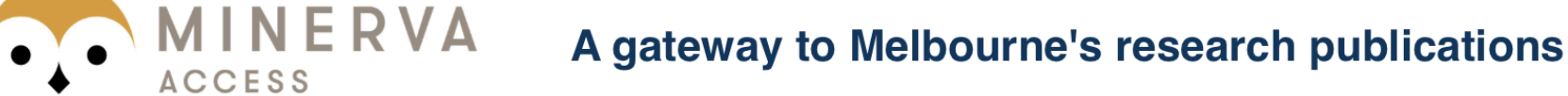

Minerva Access is the Institutional Repository of The University of Melbourne

Author/s:

Nie, P-Y;Wang, C;Meng, Y

Title:

An analysis of environmental corporate social responsibility

Date:

2019-06-01

Citation:

Nie, P. -Y., Wang, C. \& Meng, Y. (2019). An analysis of environmental corporate social responsibility. MANAGERIAL AND DECISION ECONOMICS, 40 (4), pp.384-393. https:// doi.org/10.1002/mde.3009.

Persistent Link:

http://hdl.handle.net/11343/286835 